\title{
El pensamiento de Sócrates (470-399)
}

\author{
Héctor Samour \\ Catedrático, investigador \\ Exviceministro de Educación
}

\section{Sócrates, ¿qué Sócrates? El problema socrático}

El testimonio de Nietzsche: era tan feo hasta el punto de que Nietzsche se pregunta si era verdaderamente un griego, si no representa al criminal típico, con su maldad raquítica: "Todo en él es exagerado, burdo, caricaturesco; y al mismo tiempo lleno de escondrijos, de segundas intenciones, de subterfugios".

Sin embargo, su fealdad atrae a Alcibíades. Caminaba con los pies descalzos. A veces se le presenta como sucio, aunque recomendaba la limpieza a los jóvenes adolescentes. En resumen, una especie de mendigo (¿de qué vivía? No cobraba sus lecciones) al que quizá alguna vez (¿qué no se ha dicho de Sócrates?) le dieron una paliza, sin que dejara de sonreír, por la exasperación que causaba en el ágora su manía de discutir.

Le gustaba bailar, tañía la lira; y en el Fedón, Platón nos lo muestra como poeta. También asombraba por su naturaleza demoníaca: "detente", "anda", y andaba y se paraba según las órdenes que le daba su daimon (genio). Casi nunca salió de Atenas, más que para defenderla contra los persas, en Delion (donde salva a Jenofonte), en Potidea, y para consultar el oráculo de Delfos ("Sócrates es el más sabio de los mortales", "Conócete a ti mismo").

El contexto sociopolítico está marcado por el auge y la caída de Atenas como cabeza política del mundo helénico. A pesar de todos los testimonios contrarios, a Sócrates se le presenta con una preocupación terapéutica moral por el ser humano y por las instituciones sociales y políticas de la ciudad, despreciando el beneficio material personal para dedicarse a convencer a los atenienses a "prestar atención a la virtud" (Apología, $31 a-b)$.

\section{¿Existe una filosofía de Sócrates?}

El testimonio platónico es la mejor fuente para conocer la filosofía socrática, sobre todo en los diálogos tempranos, especialmente en la Apología y en el Critón (escritos en el tiempo de su muerte; entre 399 y 394).

Sócrates, a los 70 años (en el 399), es acusado y condenado por su intervención filosófica en la polis, porque lo han acusado según lo que parecía y no según lo que era: 
Hablaban de cierta especie de sabio, llamado Sócrates, investigador de los fenómenos celestes y que hay en las profundidades de la tierra, y transformador de argumentos débiles en fuertes. Los que han propalado esa noticia, esos son, atenienses, mis acusadores temibles, pues quienes les oyen consideran que los que se dedican a tales investigaciones tampoco creen en los dioses. (Apología, $18 b)$.

"Sócrates delinque: corrompe a los jóvenes; no reconoce a los dioses de la ciudad, y, en cambio, tiene extrañas creencias relacionadas con los genios" (daimonia) (Apología, 24b).

La ciencia de Sócrates es una ciencia humana (anthropine sophía); y no como la de los otros, una ciencia más que humana (cf. Apología, 20e):

El oráculo de Delfos dijo que no había nadie más sabio que Sócrates. Cómo puede ser el más sabio quien tiene conciencia de no serlo ni grande ni pequeño. Se puso a comprobarlo (Cf. Apología, 21 a-b). "Fui a buscar hombres que pasaban por sabios. Ante todo, un político (tis ton politikon), y al demostrarle que no sabía nada, que no era sabio, me gané su enemistad" (Apología, $21 \mathrm{c}-\mathrm{d}$ ). "Los poetas como los profetas y los adivinos dicen cosas bellas, pero no saben lo que dicen" (Apología, 22 a-c). "Los artesanos porque sabían bien su oficio, creían saberlo todo bien" (Apología, 22 d). "Soy más sabio que todos ellos en cuanto no creo saber lo que sé. Es por dar razón al dios que yo demuestro a la gente su ignorancia y me gano su enemistad" (Apología, 23 a-b).

La misión de Sócrates la ha adoptado porque su preocupación es hacer lo que es justo y lo que su vocación divina le exige:

Ahora bien: tal vez parezca chocante el hecho de que yo, como es sabido, vaya por doquier aconsejando en privado del modo referido y metiéndome en cosas ajenas, $y$, en cambio, no me atreva a subir ante vuestra Asamblea para aconsejar públicamente a la ciudad. Más la causa de ello es lo que muchas veces me habéis oído decir en muchos lugares, que sobre mí siento la influencia de algún dios y de algún genio [...] se trata de una voz que comenzó a mostrárseme en mi infancia, la cual siempre que se deja oír, trata de apartarme de aquello que quiero hacer y nunca me incita hacia ello. Eso es lo que se opone a que yo me dedique a la política, y me parece que se opone con sobrada razón. Podéis estar seguros, atenienses, de que, si yo me hubiese puesto hace tiempo a intervenir en la política, tiempo ha que se me habría dado muerte y ni a vosotros ni a mí mismo habría sido útil en cosa alguna (Apología, 31 d-e).

Agradezco vuestras palabras y os estimo, atenienses, pero obedeceré al dios antes que a vosotros y, mientras tenga aliento y pueda, no cesaré de filosofar, de exhortaros y de hacer demostraciones a todo aquél de vosotros con quien tope con mi modo de hablar acostumbrado, y así, seguiré diciendo: "Hombres de Atenas, la ciudad de más importancia y renombre en lo que atañe sabiduría y poder, ¿no te avergüenzas de afanarte por aumentar tus riquezas todo lo posible, así como tu fama y honores, $y$, en cambio, no cuidarte ni inquietarte por la sabiduría y 
la verdad, y porque tu alma sea lo mejor posible?", y si alguno de vosotros se muestra en desacuerdo conmigo y asegura preocuparse, no lo dejaré marcharse al punto ni yo me alejaré, sino que le haré preguntas, lo examinaré, le pediré cuentas, y, si no me parece estar en posesión de la virtud, aunque lo diga, le echaré en cara su poco aprecio de lo que más vale y que estime en más lo que es más vil [...] Pues eso es lo que ordena el dios, sabedlo bien, y yo considero que no habéis tenido en la ciudad hasta la fecha un bien mayor que mi labor al servicio del dios.

Sin embargo, me he abstenido de entrar en los asuntos públicos:

Que hay una perfecta armonía entre mi conducta y el hecho de haber sido entregado a la ciudad por el dios, podéis conocerlo por esto: no cuadra bien a cosa humana el que yo no me haya cuidado de ninguno de mis intereses y haya permanecido indiferente durante años ante el descuido de todo lo de mi casa y, en cambio, haya trabajado siempre en interés vuestro, acercándome en privado a cada uno de vosotros [...] para tratar de moveros a prestar atención a la virtud. Y si yo hubiese obtenido de esto algún provecho y os hubiese dado estos consejos a cambio de una paga, habría tenido alguna razón personal para obrar asi [...] Y de que esto es así presento un testigo que considero fehaciente: mi pobreza (Apología, 31 a-c).

Los discípulos de Sócrates:

Pero yo jamás fui maestro de persona alguna, sino que, cuando alguien, sea joven, sea viejo, desea oírme hablar o presenciar mi modo de comportarme, nunca pongo obstáculos, ni tampoco soy persona que converse mediante estipendio y se niegue a dialogar sin él, ya que lejos de eso, me pongo a disposición de todos, del rico como del pobre, para que todo el que quiera escuche lo que digo al responder (Apología, 32 a).

La recompensa que le da la ciudad por este servicio constante:

[...] qué castigo debo sufrir o qué multa pagar por no haber tenido en la vida punto de reposo, por haberme despreocupado de aquello que constituye la preocupación de la mayor parte de los hombres, las ganancias, el gobierno de la casa, el generalato, los discursos ante el pueblo, todos los cargos públicos, las conjuraciones y las disensiones que en la ciudad vienen teniendo lugar, por haber creído que yo era demasiado honrado para conservar la vida, si me dedicaba a estas actividades, por no haber ido a aquellos lugares en los que no habia de reportar utilidad alguna ni a vosotros ni a mí mismo, y haber acudido a donde os podia ocasionar los mayores beneficios, como ya os he dicho, de manera privada: por haberme esforzado por convencer a cada uno de vosotros de no debía cuidarse de ninguna de sus cosas antes de procurar ser lo mejor y lo más prudente posible,... ¿Y qué premio cuadra a un hombre pobre, a un bienhechor de la caridad, que se ha visto obligado a desatender sus intereses personales para dedicarse a instruiros? (Apología, 36 b-d). 
[...] Porque si digo que eso es desobedecer al dios y que por esa razón es imposible renunciar a esa actividad, no me creeréis, por considerar que se trata de una evasiva mía; si afirmo que el mayor bien para el hombre consiste en hablar día tras día acerca de la virtud y acerca de las restantes cuestiones con relación a las cuales me oís discurrir y examinarme a mí mismo y a los demás, y que, en cambio, la vida sin tal género de examen no merece ser vivida, eso me lo creeréis todavía menos (Apología, 38 a).

\section{Sócrates como modelo del aporte del filósofo a la polis}

Lo que Sócrates aporta primariamente no es un estricto saber político, sino las condiciones para un hacer político justo.

Desde luego, dedica su pensar filosófico a lo que es el ser humano, el ciudadano y la polis, sustrayéndose de aquello que está por encima y por debajo de la tierra (supuestamente lo sublime y lo profundo). Su misma idea de filosofía, como un modesto percatarse de sus propios límites, le ha hecho comprender que en los temas propiamente cósmicos poco puede alcanzar la mente humana, al menos con las técnicas que en su tiempo había.

Con esta dedicación, él o sus discípulos inician un verdadero pensar filosófico sobre alguno de los problemas fundamentales de la realidad social, tal como se pueden ver ya organizadamente en Platón. Entre estas condiciones lo esencial es que las gentes y sobre todo los políticos busquen un estricto saber, empezando por reconocer que no saben, y que procuren buscar ante todo lo que es justo.

La novedad consiste, primero, en considerar la busca de la sabiduría como una forma ética y religiosa de vida. Expresión de una vida auténtica. Segundo, la novedad consiste en el propio en su punto de arranque: en la persuasión de que poco es lo que el ser humano sabe, y de para que empezar a saber el primer paso es percatarse de la propia ignorancia. Este es el sentido de la ironía socrática. Tercero, en su método de preguntas y respuestas, los métodos del diálogo y de la mayéutica, supone que la verdad no debe ser enseñada sino encontrada por cada uno; que no se trata de disputar opiniones sino de ir modestamente a oír lo que las cosas le dicen al ser humano; hay que vivir no solitario, pero sí recogido de la propia reflexión; y no de mera repetición de las cosas aprendidas. Cuarto, esa novedad consiste en los temas que aporta como base de la filosofía: él también busca el ser, pero lo busca allí donde le es más presente, en las cosas de la vida $\mathrm{y}$ en los asuntos humanos.

Su modo de intervención es filosófico y no estrictamente el propio de los políticos. No quiere ocupar ninguno de los cargos políticos, porque lo que busca no es ejercitar el poder sino que el poder se ejercite bien.

Su modo específico es el despertar la conciencia de los individuos como del pueblo. La conciencia tiene en Sócrates una clara dimensión de saber, pero también una dimensión de querer hacer lo justo. La justicia es algo que se sabe para hacer. Este despertar la 
conciencia de la ignorancia y la injusticia es lo que le causa enemistad y persecución.

Su modo de vida es el del olvido de sí y de lo suyo para dedicarse al bien de los otros y de la ciudad. Por fidelidad a sí mismo y a su vocación se dedica a esta misión crítica y alentadora; el gran testigo de su dedicación desprendida es su propia pobreza.

Sócrates se ha dedicado a eso por y con espíritu religioso, por obediencia a su conciencia y a la divinidad. Cree que ha sido su dios el que le ha ordenado para sus días en esa ocupación, examinándose a sí mismo y a los demás. Por ello, si para salvar su vida le pidieran que dejara a su lado la vocación, no lo haría porque debe obedecer antes al dios que a los hombres (Cf. Apología 38 e).

¿Cómo sabe Sócrates que ha sido la divinidad la que le ha mandado dedicarse al estudio de la filosofía? Por varias razones. Primera, porque hay algo de sobrehumano en el hecho de haber abandonado sus propios negocios hasta caer en la pobreza, por dedicarse a exhortar a los demás a que practiquen la virtud. Segunda, porque tiene un daimon interior que desde la infancia le urge a apartarse de lo que no debe hacer. Tercera, porque la filosofía, tal como él la ha entendido, es el mayor bien para el ser humano. Una vida que no se examina a sí misma no es vida.

Lo que busca es que la ciudad y los ciudadanos se comporten éticamente, con lo que su percepción de la política está más relacionada con lo ético que con lo técnico. Para Sócrates lo ético es, por lo pronto, un saber - y un saber estricto-, que necesita de un especialista - y un gran especialista - por la dificultad del problema político. Pero el objetivo no es el de lograr una persona y una ciudad rica, sino unas personas y una polis justas.

Desde aquí se explican sus principales tesis éticas:

1. No es la fortuna la que hace la virtud, sino la virtud la que la hace la fortuna y todo lo que es bueno, tanto a los individuos como a la ciudadanía.

2. Evitar que se cometan injusticias e ilegalidades; evitar hacer el mal.

3. Preocuparse más de lo que son los ciudadanos y la ciudad, que de lo que tienen más de ellos mismos que de lo que es de ellos.

4.El comportamiento ético traería los bienes materiales y la felicidad, y no al revés.

Sócrates está persuadido que el mayor bien del ser humano no consiste en atender a las cosas que le pertenecen, a las que posee, sino más bien a lo que es el él mismo. Las riquezas y los honores se tienen y son algo exterior al hombre, pero el ser más sabio y más perfecto es algo que se es, y se es desde dentro. Por ello, solo una gracia tiene que pedir a los atenienses que lo condenan a muerte ( $C f$. Apología, $41 \mathrm{e})$.

Solo la divinidad sabe si es mejor vivir o morir. Temer a la muerte no es otra cosa que creerse sabio sin serlo. Nadie sabe lo que es la muerte ni sabe si es el mayor bien para el ser humano. Se le teme, como si se supiese con certeza que es el mayor de todos los males. ¿No es esto una ignorancia vergonzosa creer conocer una cosa que no se conoce? Sin embargo, a su sus puertas, Sócrates siente una esperanza profunda de que 
la muerte es un bien. Porque, o es un absoluto anonadamiento y una privación de todo sentimiento, o es un tránsito del alma a donde se le va a tratar con toda justicia.

En el comportamiento ético tiene especial significado la aceptación de las leyes de la ciudad, pues el que quiere vivir en la ciudad debe querer vivir según sus leyes. Sócrates sí ve la diferencia entre la ley y la justicia, y, sobre todo, entre estas y el modo de gobernar y de hacer justicia por los que están en el poder. Pero su manera de actuar es, sobre todo, para que cambien las leyes y los comportamientos de quienes las ejecutan.

La intervención filosófica en la realidad política resulta estrictamente política. Se convierte en fuerza pública no en cuanto pura teoría, sino en cuanto teoría comunicada. Desata comportamientos individuales, pero son comportamientos hechos públicos y, consiguientemente, incidentes en la realidad pública.

La muerte de Sócrates, tal como la presenta Platón, es prueba de la peligrosidad pública de un pensamiento filosófico entendido como pensamiento político - y políticamente efectivo- Es la propia vocación filosófica la que, sin salir de sí, lleva a ocuparse con la realidad política para lograr su transformación.

\section{Recapitulación de la filosofía socrática}

Sócrates da un impulso nuevo a la filosofía. Ante todo, porque es su vida entera la que va a dedicarse a la filosofía, con lo cual esta se convierte en una forma de vida, en la que se apoya y desde la que se dirige la propia existencia humana.

En segundo lugar, porque la filosofía no es en sus manos un presuntuoso saber ni una mera transmisión de verdades ya logradas, sino un permanente inquirir en el que predomina el convencimiento de los propios límites intelectuales.

La ironía socrática puede considerarse como un recurso para triturar al adversario, pero es en el fondo el reconocimiento de la dificultad y de la autenticidad propia del filosofar. Cuando Sócrates emplea la mayéutica como ayuda para que cada cual encuentre sus propias ideas está reconociendo que todos los seres humanos pueden ir en busca de la verdad y, a la par, que la verdad solo nace desde dentro. La mayéutica representa, por tanto, el debido contrapeso a la 'ironía'. Finalmente, Sócrates introduce lo humano en la filosofía como interés principal y como lugar donde puede adquirirse un auténtico conocimiento. Ese es el sentido profundo del 'conócete a ti mismo', que ya andaba en boca de los atenienses, pero que Sócrates ha elevado a categoría y método filosófico.

Lo que hicieron Platón y Aristóteles fue continuar el camino que Sócrates había abierto. Sócrates les enseñó a reflexionar sobre las cosas usuales y próximas al ser humano con el fin de radicar la filosofía en algo que de verdad importe al hombre; les enseñó a reconquistar el saber racional perdido en nebulosidades; les abrió el camino para que cada uno a su modo alcanzara una visión sistemática de la totalidad del universo.

Pero también Sócrates dio a la filosofía varias ideas maestras. Primera, la de un nuevo 
método. Dice Dilthey que fue el primero que aplicó tenazmente el método que consiste en remontarse desde el saber existente y las creencias de la época al fundamento de cada proposición. En otras palabras, sustituyó un procedimiento que deducía construcciones geniales por un método que refería toda afirmación a su fundamento lógico: “[...] En él nació en la historia de la inteligencia el método analítico que se remonta al último fundamento cognoscitivo del contenido de la ciencia y, finalmente, de la convicción científica general” (Introducción a las Ciencias del Espíritu, Madrid, 1966, pp. 277278).

¿En qué consistía el método práctico de Sócrates? Su forma era la de una dialéctica o diálogo. Que este método se llevara a cabo mediante el diálogo muestra que es necesaria cierta dialéctica entre razones o argumentos, mediante la cual aparece la 'sinrazón' de una de las posiciones. Pero muestra también, como ya hemos notado, que la verdad es resultado de una búsqueda personal.

Segundo aporte: la idea de una cierta inducción, que da paso a los conceptos universales y a la definición. Aristóteles nos dice: "Dos cosas hay que atribuir con justicia a Sócrates, por un lado los epantikoi logoi y por el otro el oridsesthai katholou" (Metafísica, 1078b). Esto es, "procesos inductivos" y "resultados de la inducción". La definición sería el resultado de la inducción. La definición es algo universal que respondería a los casos particulares examinados. Ciertamente, el Sócrates de Platón sigue un proceso inductivo: empieza examinando los casos particulares; en ellos se fija en sus notas comunes, y con ellas logra un concepto que es común, y en este sentido universal, a todos los casos examinados. Pero Sócrates no se detiene en cualesquiera notas comunes, sino en aquello que es común por ser esencial, es decir, en aquello que es siempre igual en cada caso particular porque es la raíz de todo lo que es la cosa en particular. Con ello se logra la definición de valor universal porque expresa la esencia $-\mathrm{y}$ solo la esencia— de los distintos casos particulares.

Sin embargo, no hay que ubicar a Sócrates en la pura especulación metafísica. Por lo menos el Sócrates histórico no busca la esencia de la virtud como si aquella fuera el fundamento ontológico e inmutable de la virtud en sí. Se trataría más bien de la delimitación de la "esencia" del valor a través de la exploración de lo que todos entienden cuando hablan del valor. Se trata de un procedimiento inductivo, que va procediendo desde una definición menos adecuada hasta otra más adecuada, o de la consideración de ejemplos particulares a una definición universal; pero el sentido y la referencia se confunden en el plano del lenguaje. Nunca Sócrates trata del conocimiento de esencias físicas o metafísicas, con estatus ontológico propio. Se trata más bien de una búsqueda dialéctica tras una adecuada definición de lo virtuoso, es decir, de un análisis semántico de las expresiones éticas, lo que conduce al enfrentamiento de los diversos criterios ofrecidos por los interlocutores de Sócrates.

El término esencia tenía en el lenguaje ordinario el significado de eidos o ti estí, es decir, términos sin alcance metafísico que únicamente significaban un conjunto de rasgos que caracterizan el "aspecto" de algo. En esta línea, lo que Sócrates indagaba era ver si era posible encontrar un nexo de rasgos comunes a varias cosas, gracias al cual 
una pluralidad de ejemplos pudieran ser englobados en un concepto único y unívoco que significaría la "esencia" o la "forma" de aquellos.

En los diálogos socráticos de Platón, sin embargo, queda bien claramente manifiesto el fracaso a este respecto de la investigación socrática en ese pretendido intento. Todo el proceso de la dialéctica socrática solo una cosa deja clara: el propósito de Sócrates de revisar críticamente el código de ideas morales de la polis, haciendo caer a los atenienses en la cuenta acerca de la inviabilidad del conjunto de valores en el que se movían.

Es el Sócrates platónico el que da a la imagen una dialéctica socrática creadora de soluciones definitivas que llevan, en última instancia, al establecimiento de un orden ideal absoluto dotado por sí mismo de validez universal.

Tercer aporte: una determinada idea de la moral. Sócrates pretende buscar lo propio del valor moral, como algo distinto de lo que es meramente útil o agradable. La moral para Sócrates está estrechamente relacionada con el saber, pero un saber que tiene el estilo del saber propio de la técnica. En el mundo de la técnica (techne) el saber es un saber hacer. El buen artesano es el que sabe bien su oficio. Y el que sabe bien su oficio no lo hace mal sino bien. En este sentido ha de entenderse su famoso pensamiento de que nadie peca (yerra) a sabiendas. Casi se trata de una tautología, pues efectivamente el que sabe no yerra, mientras que el que no sabe no acertará a hacer bien su obra. Es un "intelectualismo ético" que parece encontrarse en contradicción con los hechos de la vida diaria. ¿No tenemos acaso conciencia nosotros mismos de que muchas veces hacemos deliberadamente cosas que sabemos que están mal? Cuándo criticamos a alguien responsabilizándolo de una acción mala, ¿no pensamos que la ha cometido a sabiendas de que era mala?

En ellas se da poco juego a la voluntad y libertad humanas; si el determinismo no es absoluto, la falta no puede reducirse al yerro. La misma naturaleza humana fuerza la bondad de la conducta humana. Ya hay unas exigencias innatas en el ser humano, y lo único que hay que hacer es conocerlas para ordenar nuestro comportamiento (iusnaturalismo). Lo novedoso de Sócrates es que estas exigencias o normas de conducta las debe conocer uno mismo por sí mismo, convirtiéndose de este modo cada uno en su propio juez y árbitro.

En este sentido, la dialéctica socrática pretende mostrar el modo de guiar la propia reflexión sobre las exigencias del "alma", cuyos resultados se confían luego, sin embargo, a la propia decisión moral de cada individuo.

En este sentido, Sócrates es el representante de la autarquía moral, según la cual el hombre virtuoso encuentra en sí mismo la única regla válida para su conducta, convirtiéndose así en centro de libertad e independencia frente a las normas exteriores y los obstáculos que sus instintos animales pudieran poner al desarrollo de su vida ética.

El comportamiento recto para Sócrates es aquel que se orienta a la verdadera utilidad del ser humano, en el sentido de que contribuye a que este logre una felicidad verdadera 
(eudemonía). En el recto obrar moral encuentra el hombre su felicidad. El obrar justamente le es de mayor utilidad al hombre precisamente porque a través de ello consigue su felicidad. Esta da la pauta para una jerarquía de valores: no es la vida ni la muerte, ni el honor, la fama o el dinero lo que importa, sino el obrar moralmente, justamente (Cf. Apología, 20 d-e).

Si la felicidad es el objetivo último perseguido en nuestras acciones, la felicidad mayor y la mayor satisfacción se consiguen en y por el ejercicio de la virtud y su conocimiento, pues conocer a esta es estar en posesión de la "ciencia del bien y del mal", de donde se origina toda felicidad (Cármides, $174 \mathrm{a}$ ). 


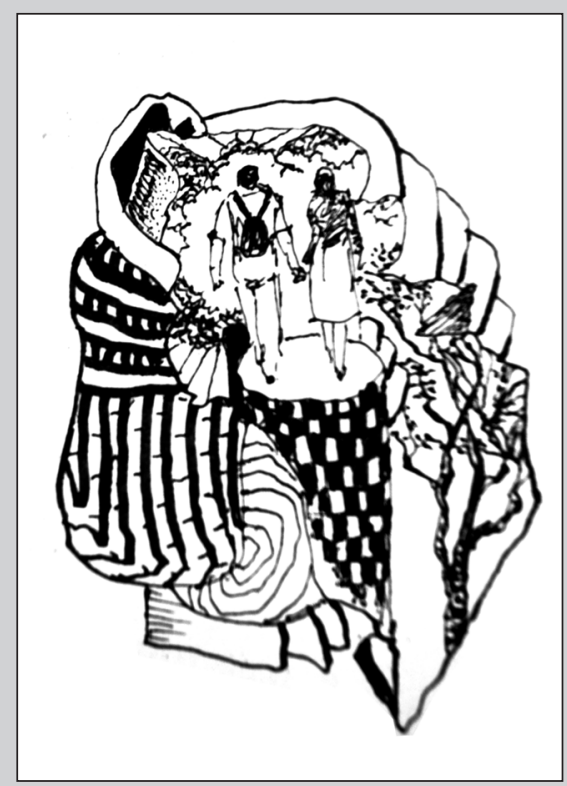

